\title{
Inhibition of ERRa suppresses epithelial mesenchymal transition of triple negative breast cancer cells by directly targeting fibronectin
}

\author{
Ying-Min Wu ${ }^{1, *}$, Zhuo-Jia Chen ${ }^{2, *}$, Hao Liu ${ }^{3}$, Wei-Dong Wei ${ }^{2}$, Lin-Lin Lu ${ }^{1}$, Xiang-Ling \\ Yang ${ }^{4,5}$, Wei-Ting Liang ${ }^{2}$, Tao Liu ${ }^{2}$, Huan-Liang Liu ${ }^{4,5}$, Jun Du ${ }^{1}$, Hong-Sheng Wang ${ }^{1}$ \\ ${ }^{1}$ Department of Microbial and Biochemical Pharmacy, School of Pharmaceutical Sciences, Sun Yat-sen University, Guangzhou \\ 510006, China \\ ${ }^{2}$ Sun Yat-sen University Cancer Center, State Key Laboratory of Oncology in South China, Collaborative Innovation Center \\ for Cancer Medicine, Guangzhou 510060, China \\ ${ }^{3}$ Cancer Research Institute and Cancer Hospital, Guangzhou Medical University, Guangzhou 510095, China \\ ${ }^{4}$ Guangdong Provincial Key Laboratory of Colorectal and Pelvic Floor Diseases, Guangdong Institute of Gastroenterology and \\ The Sixth Affiliated Hospital, Sun Yat-sen University, Guangzhou 510655, China \\ ${ }^{5}$ Institute of Human Virology and Key Laboratory of Tropical Disease Control of Ministry of Education, Sun Yat-sen University, \\ Guangzhou 510080, China \\ *These authors have contributed equally to this work
}

Correspondence to:

Hong-Sheng Wang, e-mail: whongsh@mail.sysu.edu.cn, hongshengwang@foxmail.com

Jun Du, e-mail: dujun@mail.sysu.edu.cn

Keywords: ERRa, TNBC, EMT, fibronectin

Received: April 15, $2015 \quad$ Accepted: June 16, $2015 \quad$ Published: June 26, 2015

\section{ABSTRACT}

Triple-negative breast cancer (TNBC) patients have poor prognosis due to the aggressive metastatic behaviors. Our study reveals that expression of estrogen related receptor a (ERRa) is significantly $(p<0.01)$ positively associated with high grade tumors and lymph node metastasis, while negatively correlated with overall survival (OS), in 138 TNBC patients. Targeted inhibition of ERRa by its inverse agonist XCT-790 or si-RNA obviously inhibits in vitro motility of TNBC cells. While over expression of ERRa triggers the invasion and migration of TNBC cells. Further, si-ERRa and XCT-790 inhibit the epithelial mesenchymal transition (EMT) of TNBC cells with increasing the expression of E-cadherin and decreasing fibronectin (FN) and vimentin. While XCT-790 has no effect on the expression of EMT related transcription factors such as Snail or Slug. Further, inhibitors of MAPK, PI3K/Akt, NF-KB signal molecules, which are activated by XCT-790, can not attenuate the suppression effects of XCT-790 on EMT. Alternatively, luciferase reporter gene assays and ChIP analysis indicate that ERRa can directly bind with FN promoter at ERR response element-3 (ERRE-1), ERRE-3, and ERRE-4, while XCT-790 reduces this bond. In vivo data show that ERRa expression is significantly $(p<0.05)$ correlated with FN in clinical TNBC patients. In MDA-MB-231 tumor xenograft models, XCT-790 decreases the expression of FN, inhibits the growth and lung metastasis, and suppresses the EMT. Our results demonstrate that ERRa functions as a metastasis stimulator and its targeted inhibition may be a new therapeutic strategy for TNBC treatment.

\section{INTRODUCTION}

Triple-negative breast cancer (TNBC) is defined by lack of expression of estrogen receptor (ER), progesterone receptor (PGR) and human epidermal growth factor receptor 2 (HER-2) [1]. Since the lack of common therapeutic targets, TNBCs are neither susceptible to endocrine therapy (Tamoxifen and aromatase inhibitors) nor to targeted therapeutics (Trastuzumab and Lapatinib) [1]. Further, TNBCs are associated with increased risks of metastasis and high rates of recurrence. So far there is no FDA (Food and Drug Administration)-approved targeted therapy for TNBC patients. Therefore, TNBC patients have the worst prognosis and shortest survival rates among all subtypes of breast cancer [2]. There is an urgent need to develop targeted therapy approaches for TNBC treatment. 
Epithelial-mesenchymal transition (EMT) is a developmental process in which epithelial cells lose polarity and develop a mesenchymal phenotype [3]. It has been considered as the initiation process of cancer metastasis including TNBC [3]. Tumor occurring EMT can acquire invasive mesenchymal phenotypes, increase motility and invasiveness, and infiltrate into the tumor vascular. The EMT is positively correlated with tumor progression, maintenance, drug resistance, and metastasis $[4,5]$. The progression of EMT is promoted by several important transcription factors such as Snail, Slug, Twist and Zeb [6]. Activation of multiple cellular signal pathways such as MAPK, PI3K, NF- $\mathrm{B}$, and $\mathrm{Wnt} / \beta$ catenin also can trigger the EMT process $[5,7]$. Increasing evidences show that the progression of TNBC, the most aggressive metastatic behavior of breast cancer subtype, is associated with the process of EMT [8, 9]. Further, EMT related signal pathways such as MAPK and PI3K/ Akt are highly activated in TNBC cells [10]. Therefore the inhibition of EMT might be a potential strategy to improve the prognosis of TNBC patients.

The estrogen-related receptor alpha $(\mathrm{ERR} \alpha)$ is an orphan member of the superfamily of nuclear hormone receptors [11]. It has similar structure with estrogen receptor (ER) and controls the expression of genes related to cell metabolism such as tricarboxylic acid cycle [12] and aerobic glycolysis $[13,14]$. Levels of ERR $\alpha$ have been reported to be elevated in the more-aggressive tumors in breast cancer [15-17] as well as other types of tumors [18], which are associated with a worse prognosis. XCT-790, the specific inverse agonist of ERR $\alpha$, can inhibit the proliferation of breast cancer cells $[19,20]$. The ablation of ERR $\alpha$ in knock-out mice delays ERBB2induced mammary gland tumorigenesis [21]. Further, studies revealed that inactivation of $E R R \alpha$ impairs in vitro migration of breast cancer cells [17, 22], while over expression of ERR $\alpha$ in xenografted breast cancer cells increases their metastatic capacities by induction of tumoral angiogenesis and up regulation of VEGF [23-25]. However, the roles of ERR $\alpha$ in TNBC progression and whether it is related to EMT process are still not studied.

In the present study, we show that inactivation of ERR $\alpha$ suppresses the migration and invasion of TNBC cells via inhibition the process of EMT both in vitro and in vivo. At the molecular level, we demonstrate that inactivation of ERR $\alpha$ decreases its binding affinity with the promoter of fibronectin (FN) and then down regulates the transcription of FN. Therefore, our findings suggest that inhibition of ERR $\alpha$ might represent a novel targeted therapy in TNBC metastasis.

\section{RESULTS}

\section{Expression of ERR $\alpha$ is negatively correlated with prognosis in TNBC patients}

To date there were very limited data concerning the relationship of ERR $\alpha$ expression with prognosis of TNBC patients, we then performed immunohistochemistry for ERR $\alpha$ in a set of 138 TNBC tumors. Table 1 shows that elevated ERR $\alpha$ is significantly associated with high grade tumors $(p=0.035)$ and lymph node metastasis $(p<$ $0.001)$ of TNBC. Kaplan-Meier analysis of all 138 patients demonstrated a statistically significant negative correlation between overall survival (OS) and ERR $\alpha$ expression level $(p<0.001)$. Further, statistical comparison of survival between groups with the log-rank statistic analysis suggested that patients whose tumors express increased levels of ERR $\alpha$ had poorer survival compared with those with low levels of ERR $\alpha(p<0.001)$ (Supplementary Figure S1). These data suggested that increased expression of ERR $\alpha$ resulted in a more aggressive phenotype in TNBC patients.

\section{Table 1: ERR $\alpha$ expression in 138 TNBC patients}

\begin{tabular}{|c|c|c|c|c|}
\hline Characteristics & $N$ & ERRa Low/No & ERRa High/Medium & $p$ value \\
\hline \multicolumn{5}{|l|}{ Age } \\
\hline$\leq 50$ & 66 & 37 & 29 & 0.582 \\
\hline$>50$ & 72 & 37 & 35 & \\
\hline \multicolumn{5}{|l|}{ Stage } \\
\hline $\mathrm{I} / \mathrm{II}$ & 87 & 50 & 37 & 0.236 \\
\hline III/IV & 51 & 24 & 27 & \\
\hline \multicolumn{5}{|l|}{ Grade } \\
\hline $\mathrm{I} / \mathrm{II}$ & 54 & 35 & 19 & 0.035 \\
\hline III & 84 & 39 & 45 & \\
\hline \multicolumn{5}{|l|}{ Node metastasis } \\
\hline Negative $(<10)$ & 81 & 57 & 24 & $<0.001$ \\
\hline Positive $(\geq 10)$ & 57 & 17 & 40 & \\
\hline
\end{tabular}




\section{ERR $\alpha$ facilitates the in vitro motility of TNBC cells}

Clinical data revealed that elevated ERR $\alpha$ is significantly associated with lymph node metastasis, then we investigated the roles of ERR $\alpha$ in the motility of TNBC cells. As shown in Figure 1A, the expression of ERR $\alpha$ was low in MCF-7 and T47D cells, which have little metastatic powers, while was relatively high in MDAMB-231, BT-549 and HS578T cells, which are capable of metastasizing. Then the roles ERR $\alpha$ on motility of TNBC cells were further investigated by use of in vitro wound-healing and transwell invasion assay. As shown in Figure 1B, treatment with $1 \mu \mathrm{M}$ XCT-790 for $24 \mathrm{~h}$ obviously inhibited wound closure of both MDA-MB-231 and BT549 cells as compared to the control group. Further, the number of invaded MDA-MB-231 and BT549 cells treated with $1 \mu \mathrm{M}$ XCT-790 for $48 \mathrm{~h}$ was significantly $(p<0.05)$ less than that of control cells (Figure 1C). In MDA-MB-231 cells transfected with ERR $\alpha$ construct for $24 \mathrm{~h}$, the wound closure (Figure 1D) and invaded cells (Figure 1E) were significantly $(p<0.05)$ increased as compared to the control group. To further verify the role of ERR $\alpha$ inhibition on cell motility, we knocked know ERR $\alpha$ in MDA-MB-231 cells by it specific siRNA. The results showed that si-ERR $\alpha$ significantly inhibited wound closure and in vitro invasion of MDA-MB-231 cells (Supplementary Figure S2). Cell viability analysis revealed that these treatments had no significant $(p>0.05)$ effect on the proliferation of MDA-MB-231 and BT549 cells (data not shown). Collectively, our results revealed that ERR $\alpha$ can significantly trigger the motility of TNBC cells, its inhibition or knockdown can inhibit the migration and invasion of TNBC cells.

\section{Targeted inhibition of ERR $\alpha$ suppressed the EMT of TNBC cells}

Increasing evidences show that the progression of TNBC is associated with the process of EMT $[8,9]$. We then hypothesized that ERR $\alpha$ plays a positive role in the progression of EMT. Our results revealed that MDA-MB-231 cells treated with XCT-790 (Figure 2A) or transfected with si-ERR $\alpha$ (Supplementary Figure S3) lost their spindle-like fibroblast appearance and assumed a cobblestone-like epithelial morphology. Inversely, over expression of ERR $\alpha$ was associated with an increase of aggressive cell types (Figure 2B). This was also confirmed by Western blot analysis on XCT-790 treated MDAMB-231 cells (Figure 2C) and BT-549 (Figure 2D) cells, which showed an increased expression of the epithelial cell marker E-Cadherin (E-cad), and an decreased expression of the mesenchymal cell markers FN and vimentin (Vim) via both time and concentration dependent manners. Furthermore, qRT-PCRs analysis showed that XCT-790 treatment down regulated FN while up regulated E-Cad at
mRNA levels in both MDA-MB-231 (Figure 2E and 2F) and BT-549 (Supplementary Figure S4) cells via both time and concentration dependent manners, while had limited effects on the mRNA of Vim in these two cell lines. This was also confirmed by the results that si-ERR $\alpha$ obviously prevent (Supplementary Figure S5) while over expression ERR $\alpha$ significantly promote (Supplementary Figure S6) the EMT in MDA-MB-231 cells. Collectively, these observations showed ERR $\alpha$ can trigger the progression of EMT in TNBC cells, while targeted inhibition of ERR $\alpha$ by XCT-790 suppresses this process.

\section{EMT related transcription factors and signal pathways including MAPK, PI3K/Akt, NF-kB do not mediate the suppression effects of XCT- 790 on EMT}

Since transcription factors Snail, ZEB1, Twist and Slug play essential roles in regulating EMT [4], we then investigated whether their expressions were altered in TNBC cells treated with XCT-790. Our results showed that XCT-790 treatment had no significant effect on the protein expression of Snail, Slug, Twist or ZEB1 in either MDA-MB-231 or BT-549 cells for various concentrations (Figure 3A). Cellular signal pathways including MAPK, PI3K/Akt, NF-кB, p53, Smad, and Stat3 are suggested to promote the progression of EMT in cancer cells [5]. Then their statuses in MDA-MB-231 cells treated with 5 $\mu \mathrm{M}$ XCT-790 for 30 or 60 min were checked by Western blot analysis. The results showed that XCT-790 slightly increased the phosphorylation of ERK1/2, JNK, p38MAPK, p65, and Akt, while had no obvious effect on other signalling molecules such as $\mathrm{p} 53$, Smad2, or Stat3 (Figure 3B). To verify whether ERK1/2, JNK, p38MAPK, p65, and Akt mediate the suppression effects of XCT-790 on EMT, we pretreated MDA-MB-231 cells with their inhibitor for $90 \mathrm{~min}$ and then exposed to XCT790 for another $48 \mathrm{~h}$. The results showed that inhibitors of ERK1/2, JNK, p38-MAPK, PI3K/Akt, PKA, or NF- $\mathrm{BB}$ can not attenuate XCT-790 induced FN down regulation and E-Cad up regulation (Figure 3C). Our data suggested that EMT related transcription factors and signal pathways including MAPK, PI3K/Akt, NF- $\mathrm{kB}$ do not mediate the suppression effects of XCT-790 on EMT.

\section{Targeted inhibition of ERR $\alpha$ directly inhibited the expression of $\mathrm{FN}$}

Since transcription factors and the above signal pathways did not mediated the suppression effects of XCT-790 on EMT, we then investigated whether EMT biomarkers were directly regulated by ERR $\alpha$. We analyzed the human $F N$ and $C D H 1$ (E-Cad gene) promoter sequence in silico to detect potential ERR response element (ERRE) composed of the extended ERE half-site AAGGT (or its reverse 
(A)

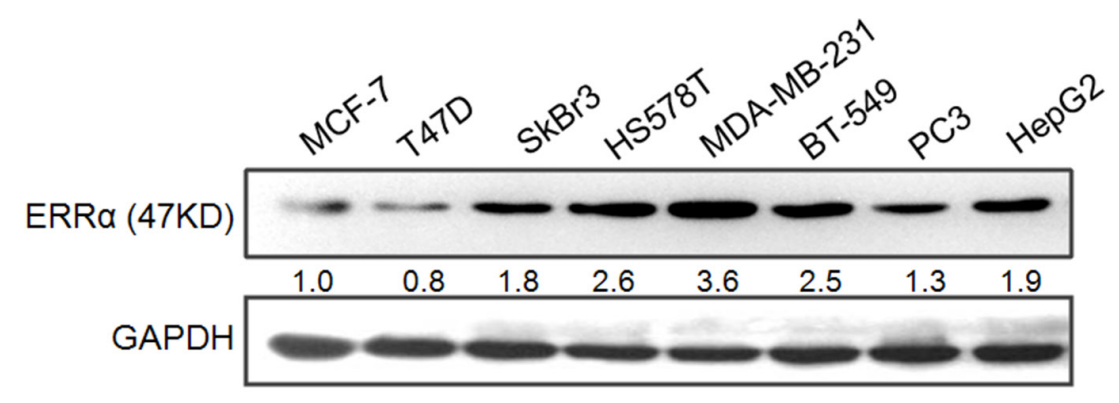

(B)
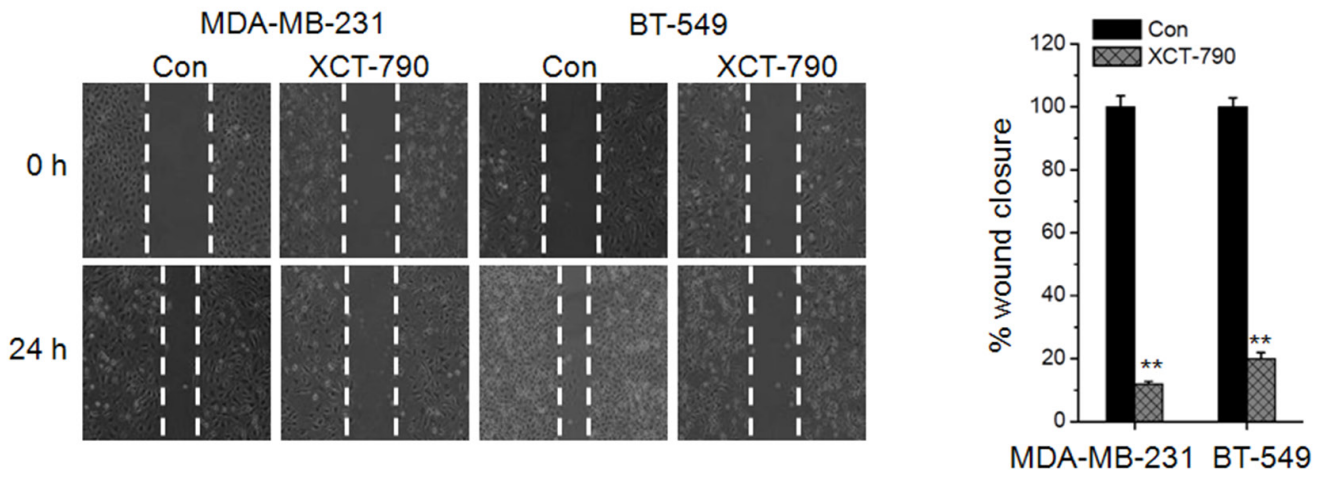

(C)
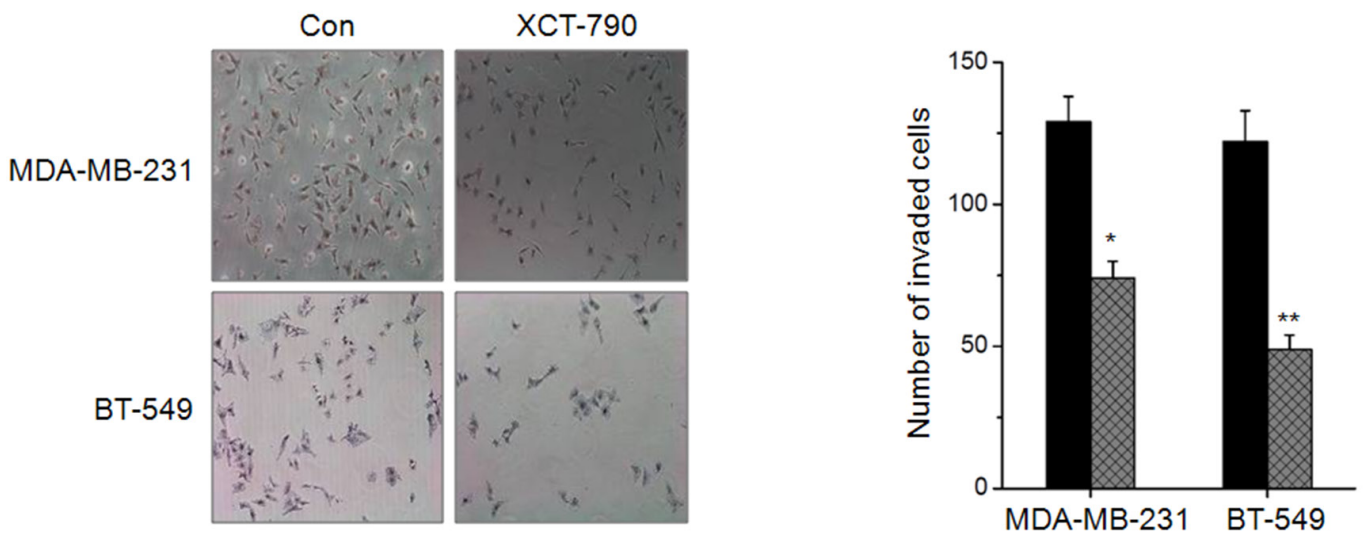

(D)
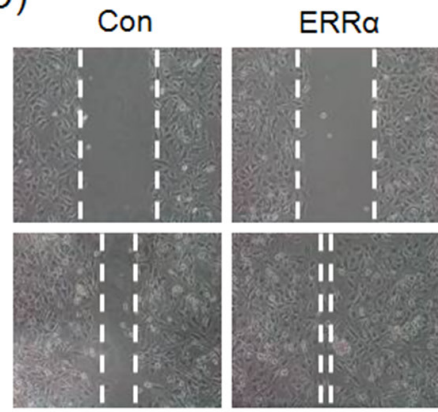

MDA-MB-231

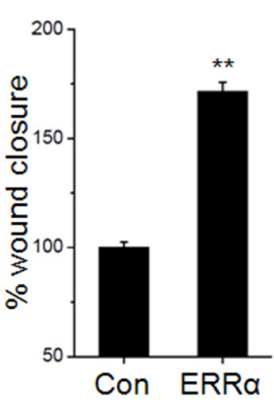

(E)
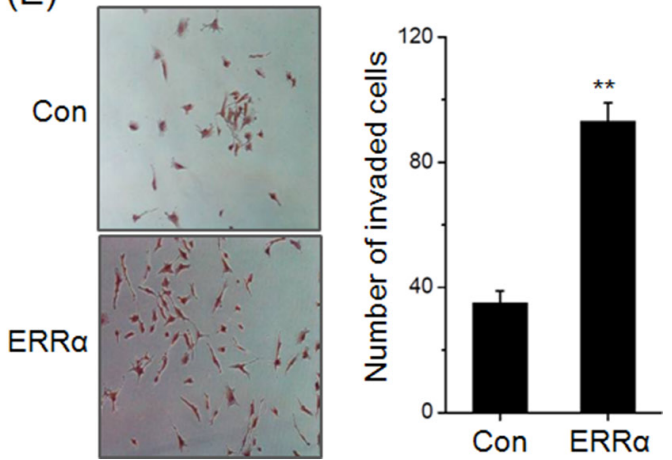

Figure 1: ERR $\alpha$ triggers the in vitro migration and invasion of TNBC cells. A. The expression of ERR $\alpha$ in human cancer cells were measured by Western blot analysis; B. Confluent monolayers of MDA-MB-231 and BT-549 cells were scraped by a pipette tip to generate wounds and then treated with $5 \mu \mathrm{M}$ XCT-790, respectively; C. MDA-MB-231 and BT549 cells were allowed to invade transwell chambers for $48 \mathrm{~h}$ in the presence or absence of $5 \mu \mathrm{M}$ XCT-790. Then invaded cells were fixed, stained, and photographed; MDA-MB-231 cells were transfected with empty vector pcDNA3.1 or ERR $\alpha$ construct for $24 \mathrm{~h}$, and then the cell motility was evaluated by wound-healing D. and transwell invasion assay E. Data represent the average of five independent experiments. 
(A)

MDA-MB-231
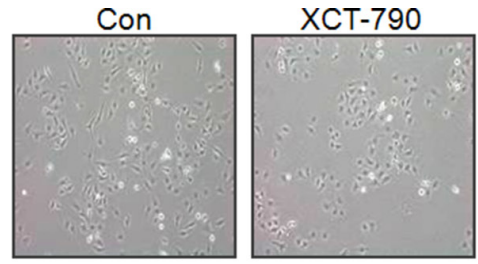

(C)

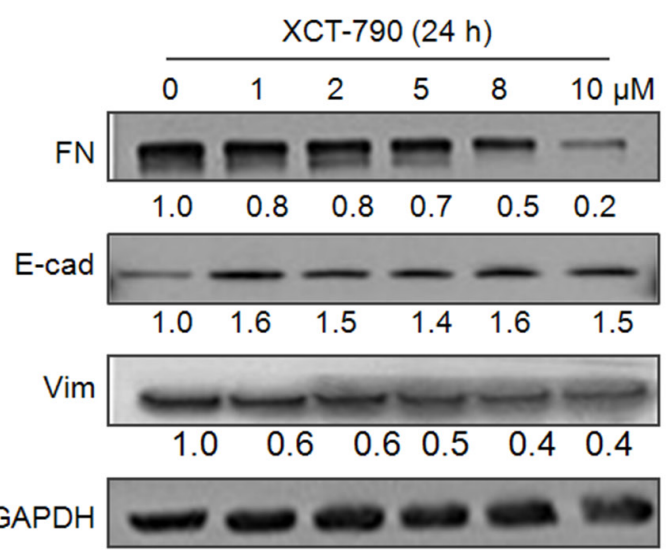

(D)

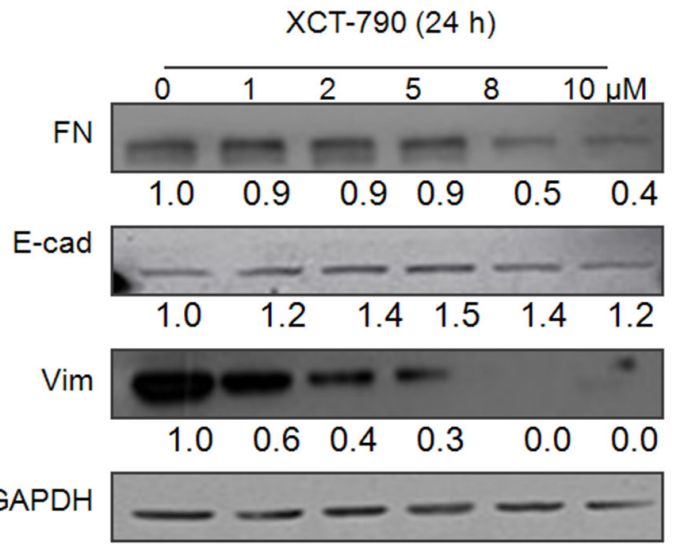

$(\mathrm{E})$

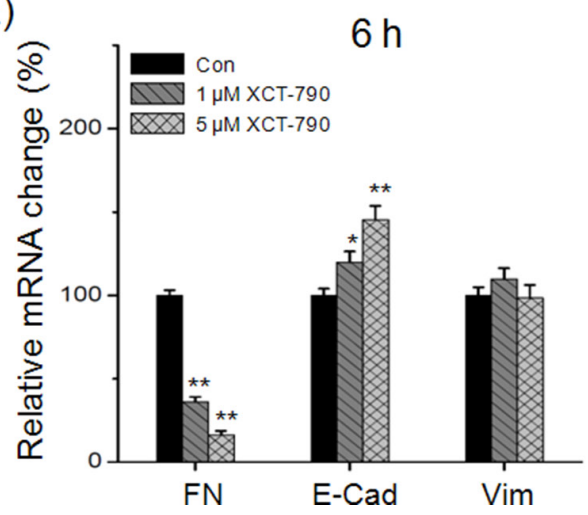

(B)

Vector

MDA-MB-231
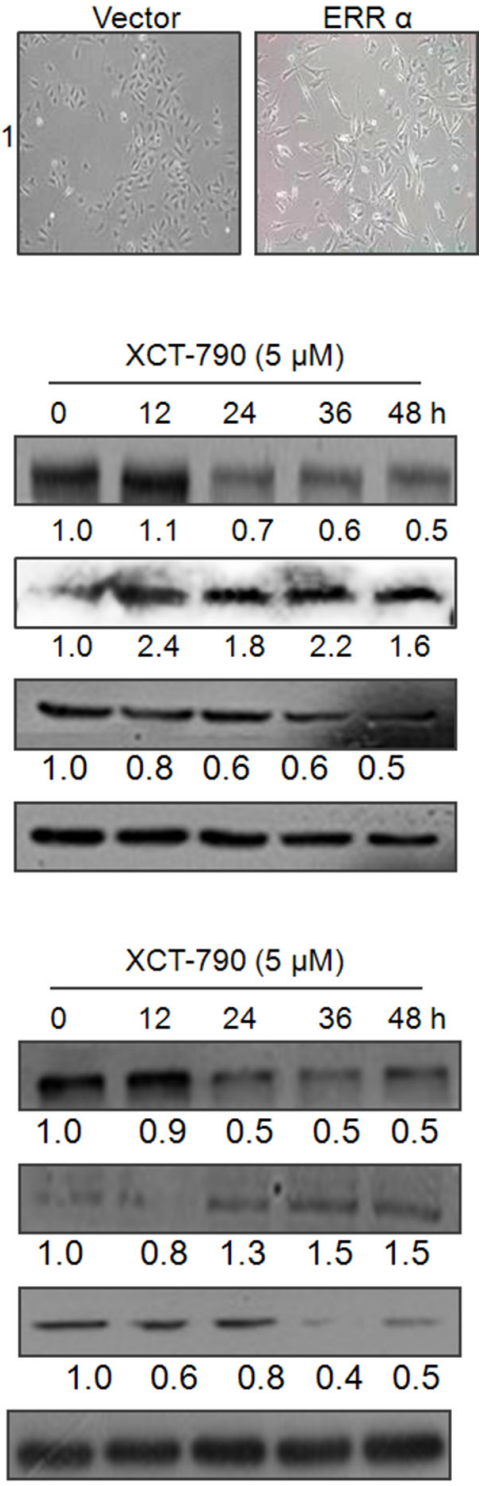

(F)

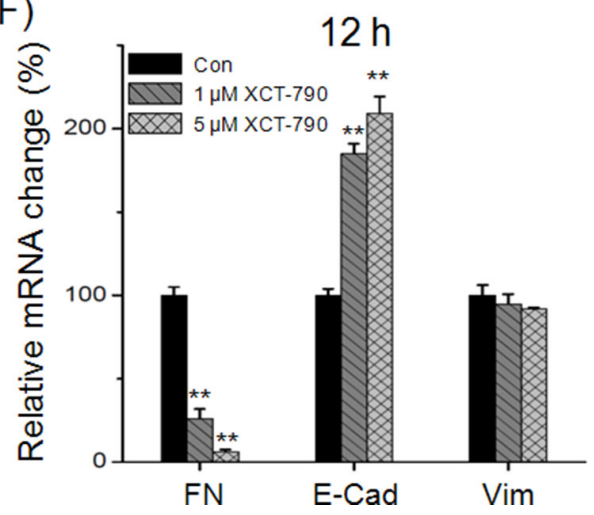

Figure 2: Targeted inhibition of ERR $\alpha$ suppresses the EMT of TNBC cells. A. MDA-MB-231 cells were treated with or without $5 \mu \mathrm{M}$ XCT-790 for $24 \mathrm{~h}$; B. MDA-MB-231 cells were transfected with pcDNA3.1 (vector control) or ERR $\alpha$ construct for 24 h; MDA-MB-231 C. or BT-549 D. cells were treated with increasing concentration of XCT-790 for $24 \mathrm{~h}$ or $5 \mu \mathrm{M} \mathrm{XCT-790} \mathrm{for} \mathrm{the} \mathrm{indicated}$ times, and then the expression of FN, E-Cad, and Vim were measured by Western blot analysis; MDA-MB-231 E. or BT-549 F. cells were treated with 1 or $5 \mu \mathrm{M}$ XCT-790 for 6 or $12 \mathrm{~h}$, then the mRNA levels of FN, E-Cad, and Vim were measured by real-time PCR. Data represent the average of three independent experiments. ${ }^{*} p<0.05$ compared with control, $* * p<0.01$ compared with control. 
(A)
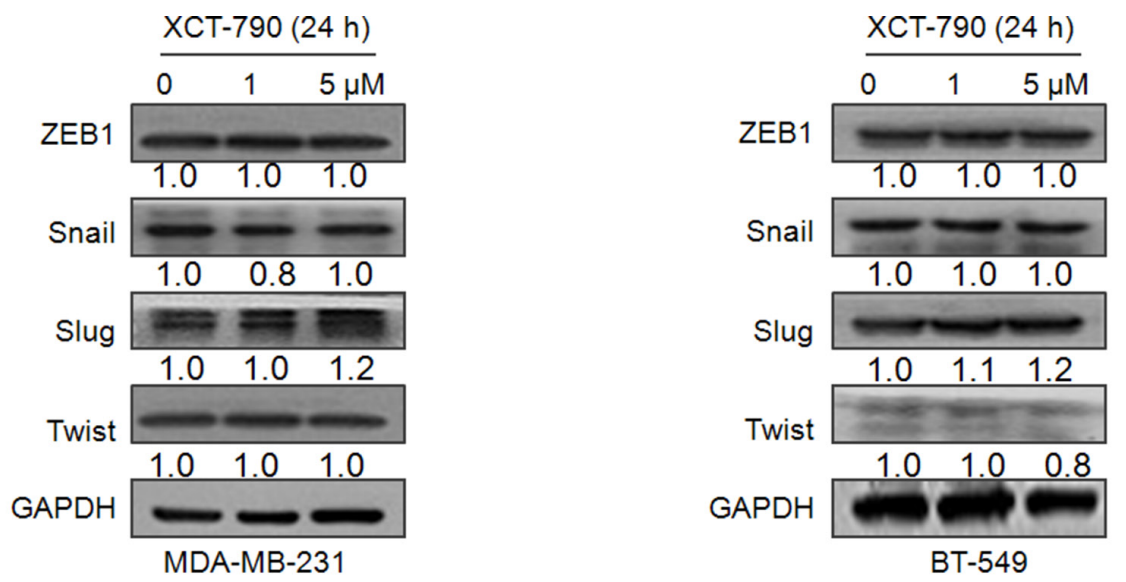

(B)
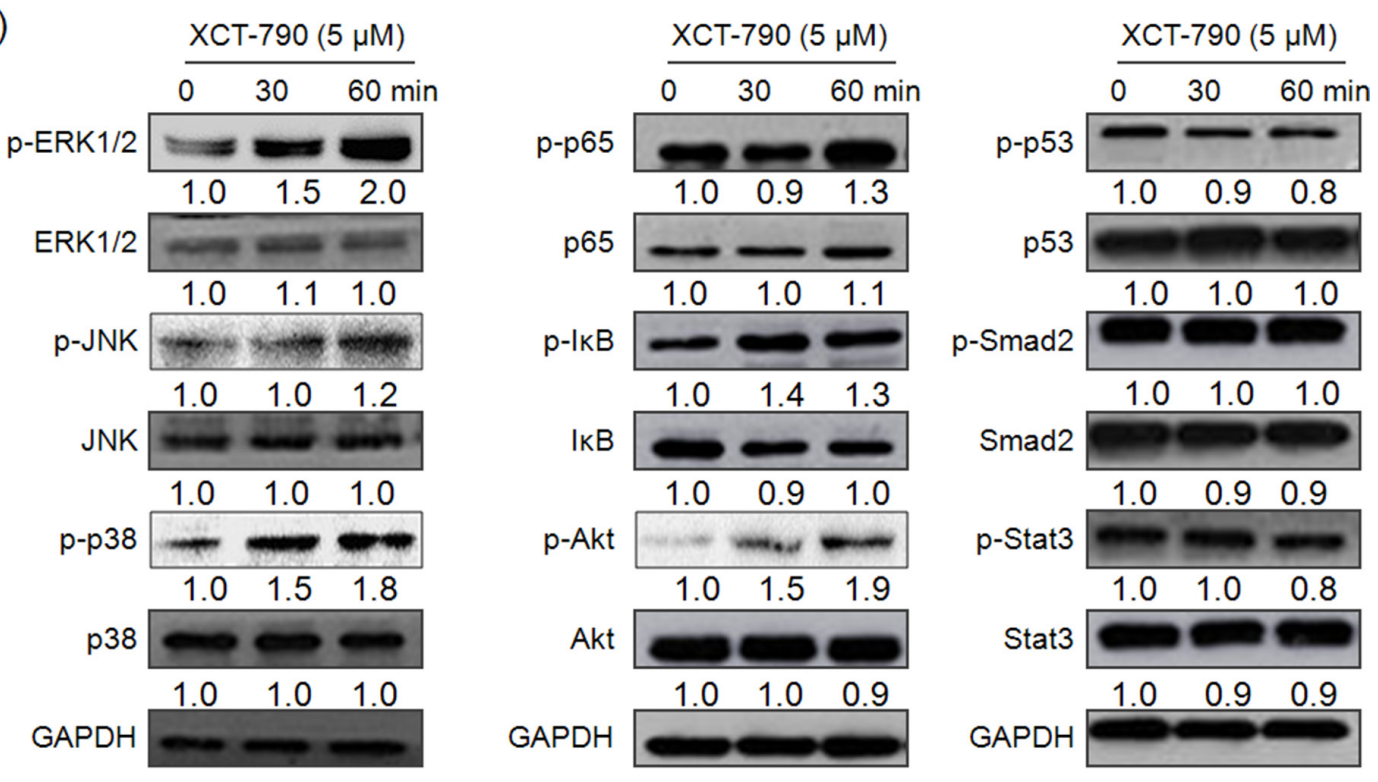

(C)
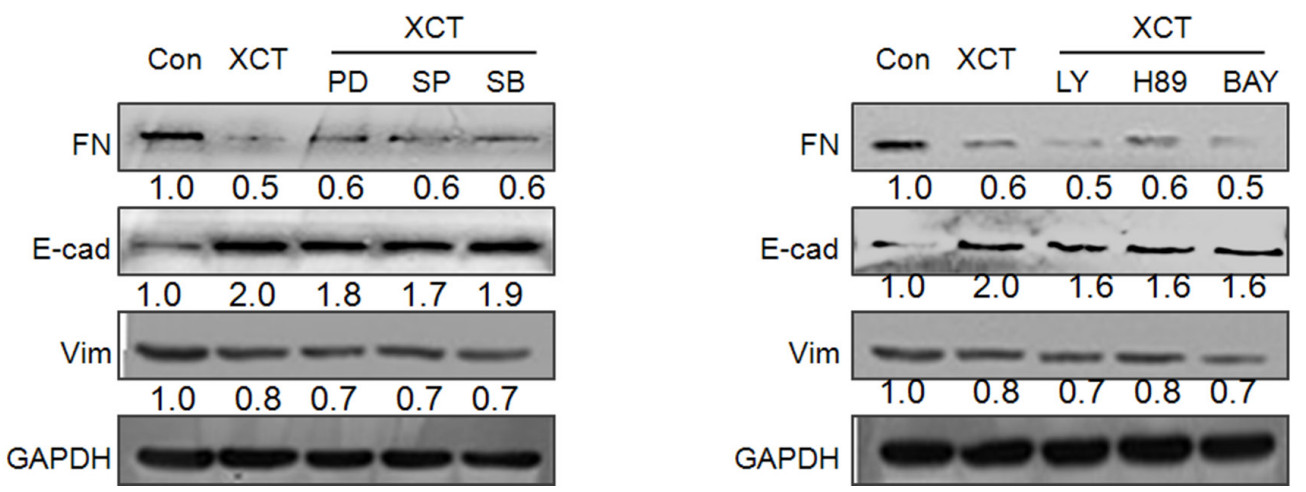

Figure 3: EMT related transcription factors and signal pathways including MAPK, PI3K/Akt, NF- $\mathrm{B}$ do not mediate the suppression effects of XCT-790 on EMT. MDA-MB-231 A. and BT549 B. were treated with 1 or $5 \mu$ M XCT-790 for 24 h, then the protein levels of Snail, Slug, Twist, and ZEB were detected by Western blot analysis; (B) MDA-MB-231 cells were treated with $5 \mu$ M XCT-790 for the indicated times, the phosphorylation and total levels of signal pathways including MAPK, PI3K/Akt, NF-кB, p53, Smad, and Stat3 were measured by Western blot analysis; C. MDA-MB-231 cells were pretreated $10 \mu \mathrm{M}$ MEK inhibitor PD98059(PD), JNK inhibitor SP600125 (SP), p38-MAPK inhibitor SB203580 (SB), PI3K inhibitor LY294002 (LY), PKA inhibitor H-89, or NF- $\kappa B$ inhibitor BAY11-7082 (BAY) for $90 \mathrm{~min}$, and then exposed to $5 \mu \mathrm{M}$ XCT-790 for further $24 \mathrm{~h}$, the expression of FN, E-Cad, and Vim were measured by Western blot analysis. Data represent the average of three independent experiments. 
complement ACCTT) $[18,26]$. As show in Figure 4A, four potential ERREs were found located within the proximal promoter of $F N$. Then we transfected the promoter reporter gene plasmid pGL3-Basic-FN-luc into MDA-MB-231 and BT-549 cells and then treated with XCT-790 for the indicated times or concentrations. Our data showed that XCT-790 significantly decreased the activity of pGL3-Basic-FN-luc in MDA-MB-231 (Figure 4B) and BT-549 (Figure 4C) cells via both time and concentration dependent manners. It suggested that XCT-790 can inactivate the promoter of FN thereby decreasing the transcription of FN.

We next performed a ChIP assay to test whether ERR $\alpha$ binds to $F N$ promoter in the native chromatin environment of TNBC cells. MDA-MB-231 cells were treated with $5 \mu \mathrm{M}$ XCT-790 for $24 \mathrm{~h}$, results showed that ChIP with a human ERR $\alpha$-specific antibody resulted in a significant decrease in the genomic fragment that contained the ERRE-1 (0.74 fold), ERRE-3 (0.78-fold), and ERRE-4 (0.67-fold) sites in the $F N$ promoter. As negative control, weak precipitation was detected with the use of no antibody or anti-rabbit IgG. Together, these data suggested that XCT-790 can inhibit the bind between ERR $\alpha$ and cis-regulatory domain of the endogenous $F N$ promoter and then suppress the transcription of FN.

\section{The expression of ERR $\alpha$ was positively correlated with FN in vivo}

In vitro analysis showed that $\mathrm{ERR} \alpha$ binds to $F N$ promoter and then activates its expression directly. To evaluate the role of ERR $\alpha$ on in vivo FN expression, we checked the relationship between ERR $\alpha$ and FN expression in 138 TNBC tumors by immunohistochemistry. Of the 138 TNBC cases, 64 had elevated ERR $\alpha$ and 75 had low levels of FN. The Fisher's exact test showed that scores for $\mathrm{ERR} \alpha$ and $\mathrm{FN}$ immunostaining were significantly correlated in $65.2 \%$ of tissues in this series $(p<0.001)$ (Table 2). This result suggested that ERR $\alpha$ expression is positively correlated with FN in clinical TNBC patients. We then examined the in vivo effect of ERR $\alpha$ on the FN expression in MDA-MB-231 tumor xenografts in nude mice by tail vein injection of XCT-790. Western blot analysis showed that XCT-790 treatment significantly decreased the expression of FN in primary tumors (Figure 5B). Generally, our data revealed that the expression of ERR $\alpha$ was positively correlated with $\mathrm{FN}$ in vivo, while its inhibition can suppress the FN expression.

\section{Targeted inhibition of ERR $\alpha$ inhibited the growth and metastasis of TNBC in vivo}

As XCT-790 can suppress in vitro migration and invasion of TNBC cells, a key question was whether targeted inhibition of ERR $\alpha$ can inhibit metastatic behaviors in vivo. We then examined the effect of
XCT-790 on metastasis of MDA-MB-231 tumor xenografts in nude mice. Our results revealed that the average size of tumor in XCT-790 group was significantly $(p<0.05)$ less than that of control ones at the end of in vivo experiment (Figure 5A). Further, Western blot analysis showed that XCT-790 treatment also significantly decreased the expression of Vim while up regulated E-Cad in primary tumors (Figure 5B). These data suggested that $\mathrm{ERR} \alpha$ inhibition suppresses the metastasis in nude mice bearing MDA-MB-231 xenografts via EMT suppression of primary tumor. Interestingly, XCT-790 treatment also decreased the expression of Snail and Slug in vivo, which was contrary to in vitro results and needed further studies. Further, XCT-790 reduced the number of metastases to the lungs by $67 \%-85 \%(p<0.05)$ compared with the control group (Figure $5 \mathrm{C}$ ). This was confirmed by histological analysis which revealed that the extent of lung metastatic lesions derived from control group was greater than that of XCT-790 groups (Figure 5D). The data supported that targeted inhibition of ERR $\alpha$ suppresses the metastasis of TNBC in vivo by EMT suppression.

\section{DISCUSSION}

Recent studies revealed that ERR $\alpha$ has a positive role in cancer cell migration and invasion [18, 21, 27]. One of the major characteristics of TNBC is aggressive migration and invasion, while the role and mechanism of ERR $\alpha$ on TNBC metastasis has not been well illustrated. Our present study reveals that targeted inhibition of ERR $\alpha$ can suppress the in vitro and in vivo motility of TNBC cells via EMT suppression by directly down regulating FN. Further, IHC results suggest elevated ERR $\alpha$ is significantly positively associated with FN expression, high grade tumors and lymph node metastasis, while negatively associated with overall survival of 138 TNBC patients. These results suggest ERR $\alpha$ activation as a mechanism of TNBC aggressiveness and imply that targeting ERR $\alpha$ may be a promising approach for TNBC treatment.

Our present study shows that targeted inhibition of $\mathrm{ERR} \alpha$ suppresses the migration and invasion of TNBC both in vitro and in vivo. This is consistent with recent studies that ERR $\alpha$ can down regulate RHOA stability [27] or induce WNT11 expression [22] to increase cancer cell migration, while knockdown of $\operatorname{ERR} \alpha$ during the early stages of zebrafish embryonic development results in inhibition of cell migration [28]. The expression of ERR $\alpha$ was also positively associated with markers of increased recurrence and adverse clinical outcome, such as increased expression of MYC oncogene, Ki-67 and AIB1 [16, 29, 30]. A molecular mechanism has been proposed linking ERR $\alpha$ to the activation of Wnt11-elicited pathway leading to increased N-cadherin expression [22], which is an important mesenchymal biomarker for cancer cells [31]. These data confirm that $\operatorname{ERR} \alpha$ plays a positive role in 

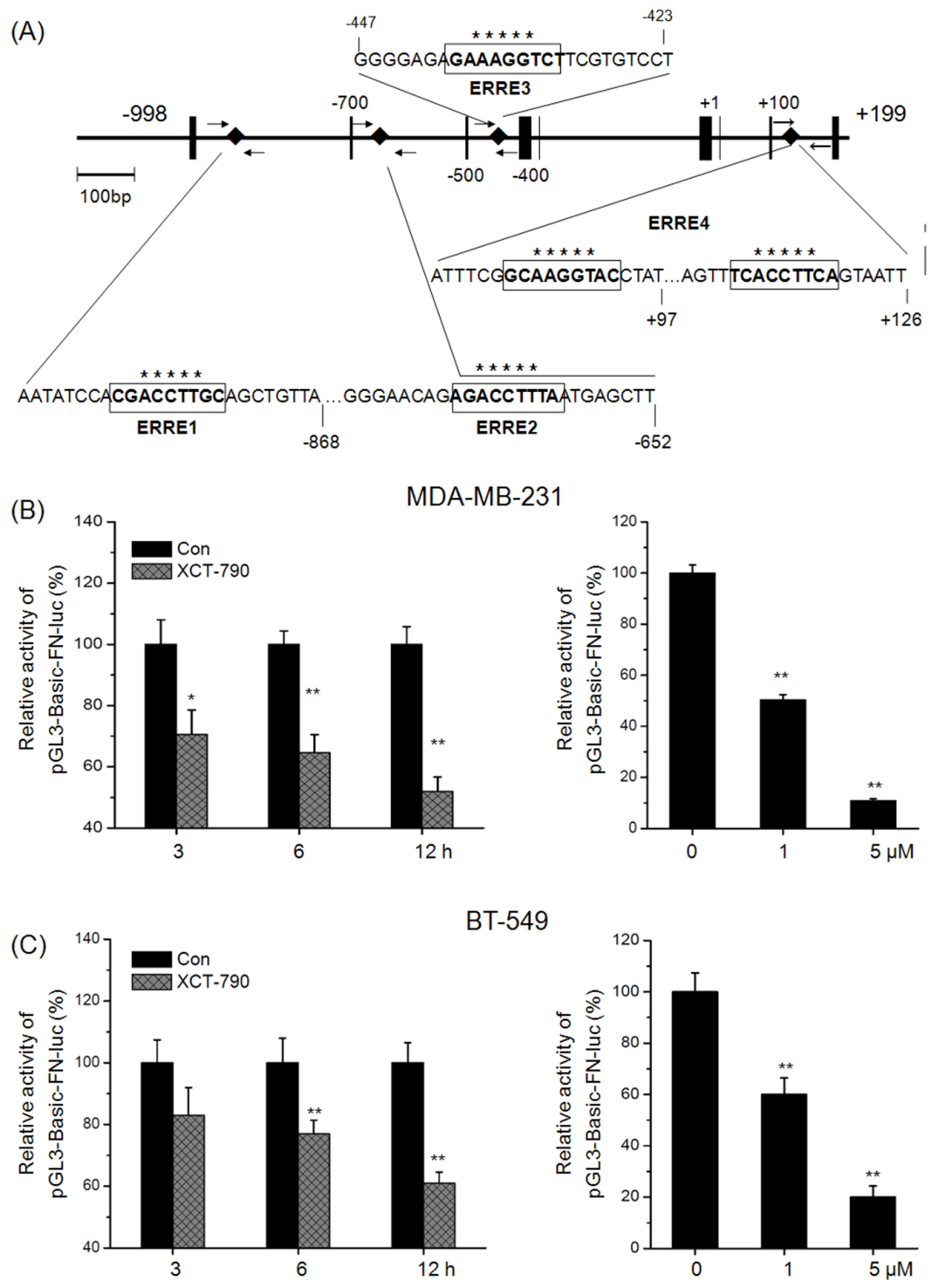

BT-549

(D)
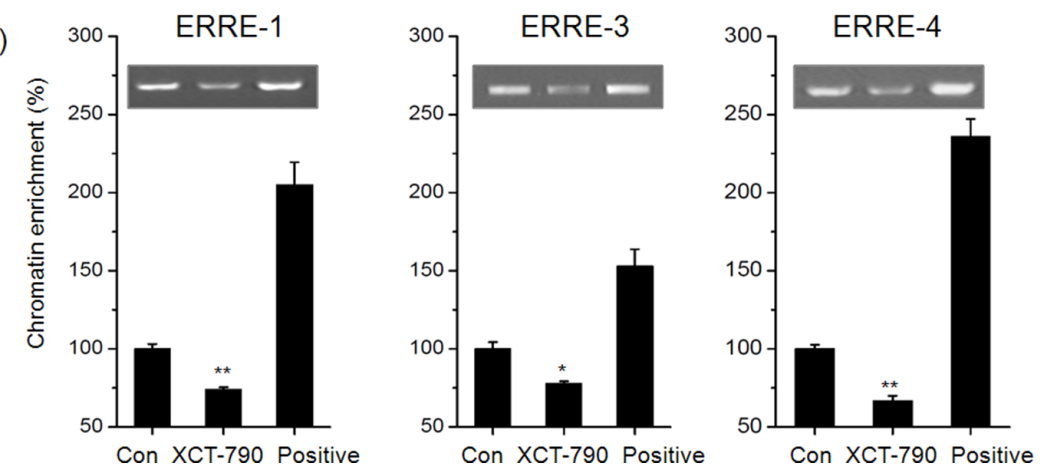

Figure 4: Targeted inhibition of ERR $\alpha$ directly inhibits the transcription of FN. A. Diagram of the human FN gene locus showing ERRE-1 4 (boxed sequences) in the promoter. Small arrows indicate the regions amplified in the ChIP experiments. MDAMB-231 B. or BT-549 C. cells were transfected with pGL3-Basic-FN-luc reporter plasmid containing FN promoter and then treated with or without XCT-790 (left column: $1 \mu \mathrm{M}$ ) for the indicated times (right column: $24 \mathrm{~h}$ ). Luminescence was measured by a luminometer. pRL-TK plasmids served as the correcting transfection efficiency. Results were expressed as the ratios between the activity of the reporter plasmid and pRL-TK. MDA-MB-231 cells were treated with or without $5 \mu \mathrm{M}$ XCT-790 for $24 \mathrm{~h}$, and then the recruitment of ERR $\alpha$ to ERREs of FN promoter was determined by ChIP. Immunoprecipitated products were amplified by qPCR, using primers indicated in Supplementary Table S1. Data are expressed relative to the amount of DNA immunoprecipitated in control cells and are the mean \pm SEM of 3 experiments. $* p<0.05$ compared with control, $* * p<0.01$ compared with control. 
Table 2: The expression of ERR $\alpha$ and FN is positively correlated in TNBC patients

\begin{tabular}{|c|c|c|c|c|}
\hline & FN Low & FN Medium & FN high & Total \\
\hline ERR $\alpha$ Low & $63^{*}$ & 6 & 5 & 74 \\
\hline ERR $\alpha$ Medium & 4 & $14^{*}$ & 6 & 24 \\
\hline ERR $\alpha$ High & 8 & 10 & $22 *$ & 40 \\
\hline Total & 75 & 30 & 33 & 138 \\
\hline
\end{tabular}

*The number of cases in which ERR $\alpha$ and FN are correlated with each other.

(A)

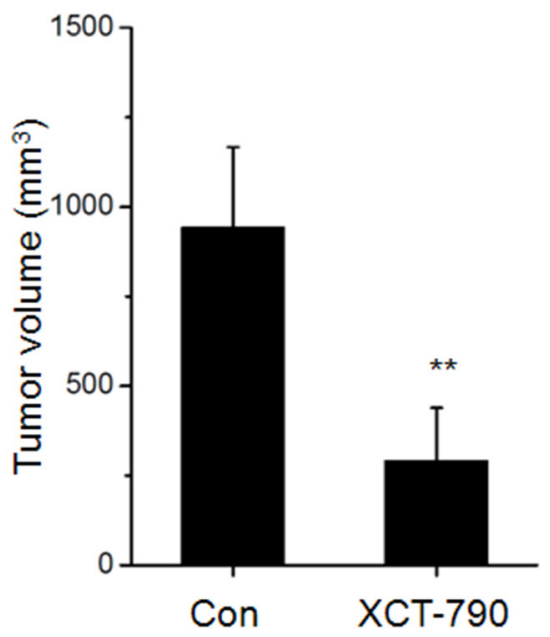

(C)

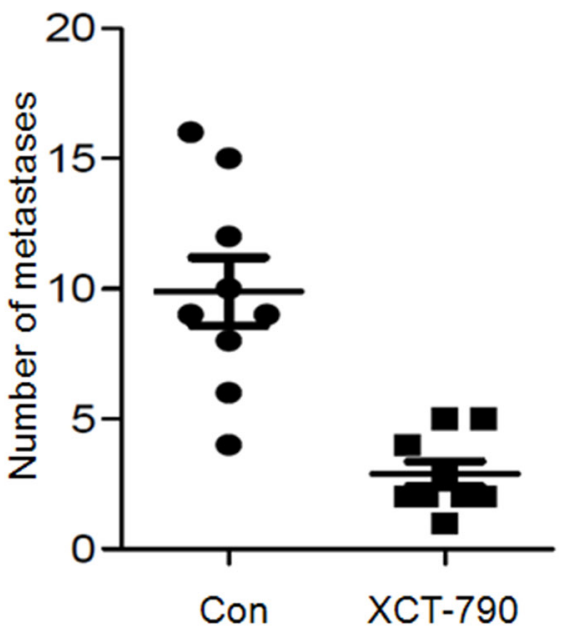

(B)

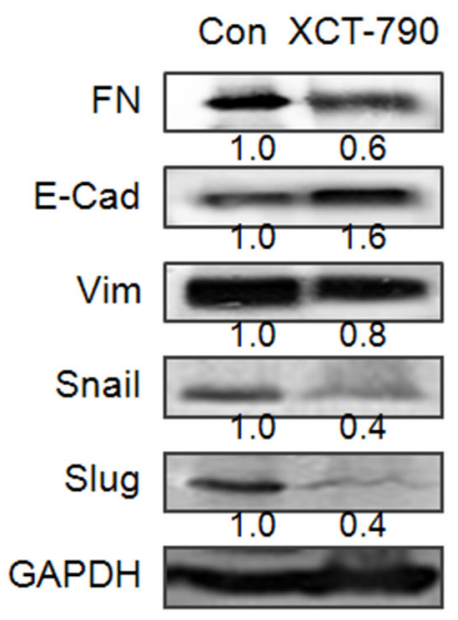

(D)

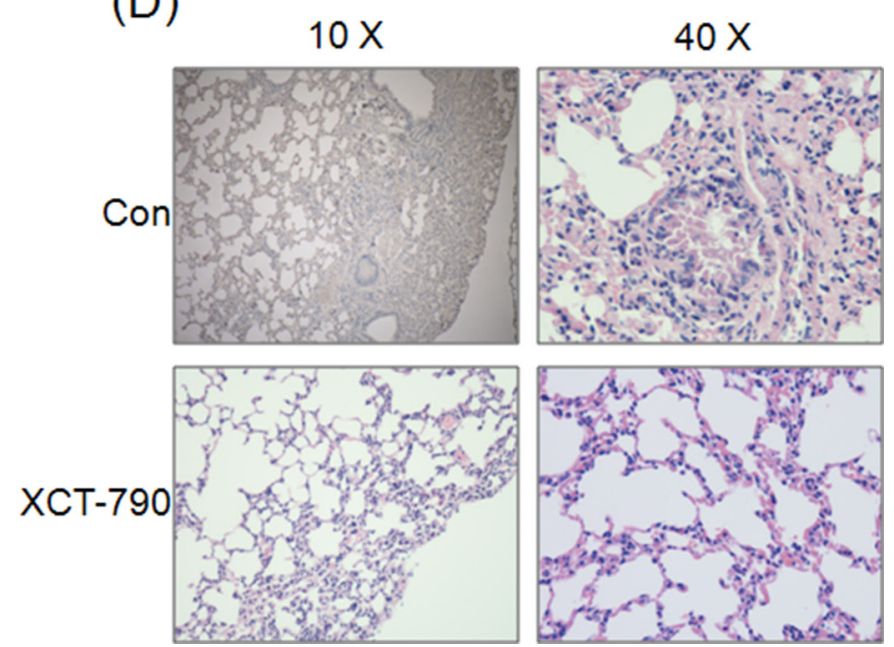

Figure 5: Targeted inhibition of ERRa inhibits the growth and metastasis of TNBC in vivo. A. The tumor volume of XCT790 and control group at the end of experiment; B. The EMT related biomarkers and transcription factors were determined by Western blot analysis in the tumor lysates from the control and XCT-790 treated group; C. Numbers of lung metastases in the control and XCT-790 treated group at the end of experiment; D. H\&E examination of metastasis in lung tissue sections of the control and XCT-790 group. ${ }^{* *} p$ $<0.01$ compared with control.

metastasis of TNBC cells, while its inhibition can suppress the motility of TNBC cells.

Most TNBC patients exhibit gene expression patterns associated with EMT [32]. EMT can endow carcinoma cells with enhanced migratory and survival abilities and is considered as the a first and key step in cancer metastasis. When the EMT process is triggered, epithelial cells lose the expression of intercellular adhesive protein E-Cad and gain the mesenchymal markers such as FN and Vim [5]. Our present results reveal that inhibition 
of ERR $\alpha$ by XCT-790 or siRNA suppressed aspects of EMT in TNBC cells. While ectopic expression of ERR $\alpha$ promotes the EMT and induction of epithelial markers. All of these data confirm the positive role of ERR $\alpha$ in EMT of TNBC cells. During this process, Vim only changed in protein level rather than RNA level, which suggests that it may just play a accompany role. Similarly, Lam et al. also suggested that targeting ERR $\alpha$ inhibits EMT and stem cell properties of ovarian cancer cells [33]. As EMTs account for the aggressiveness and stemness of TNBC, targeting the EMT-like phenotype becomes a unique strategy for TNBC treatment. It is also worth noting that high levels of $\mathrm{ERR} \alpha$ are found in various cancers such as colon, prostate, and ovarian cancers [18], suggesting that role of ERR $\alpha$ in EMT may have broader implications for other tumor cell types.

The mechanisms of ERR $\alpha$ in EMT progression are not well illustrated. Lam et al. suggested that targeted inhibition of ERR $\alpha$ inhibited the expression of Snail through both transcriptional and posttranscriptional regulation in ovarian cancer cells [33]. Inversely, inhibition of ERR $\alpha$ has no effect on EMT related transcription factors such as Snail, Slug, Twist, or ZEB. This might be due to the variation among different cancers. Further, although XCT-790 can slightly activate ERK1/2, JNK, p38-MAPK, p65, and Akt, their inhibitors have no effect on XCT-790 induced FN down regulation and E-Cad up regulation. As a transcription factor, our results indicate that XCT-790 can directly impair the bind between ERR $\alpha$ and promoter of $F N$, then decrease the transcription of FN (Figure 4). This was confirmed by the results that XCT-790 decreases the protein and mRNA levels and transcription activities of FN via both time and concentration dependent manners. The human $F N$ promoter contains four ERREs which are suggested to be bound by ERR $\alpha$, while ChIP results suggest that ERRE-1, ERRE-3, and ERRE-4 are the binding sites of ERR $\alpha$ in TNBC cells. Among the extracellular matrix (ECM) components, FN has often been used as one of the mesenchymal markers whose expression is strongly enhanced in EMT process [34]. Indeed, this is the first demonstration that ERR $\alpha$ is a directly acting transcription factor of the $F N$ gene. Although we can not exclude additional mechanisms by which ERR $\alpha$ induces FN, our present study provides another mechanism for the positive role of ERR $\alpha$ in cancer metastasis.

ERR $\alpha$ over expression is correlated with poor outcome and bad prognosis in various cancer types such as prostate, colorectal, cervical and ovarian carcinomas [35]. In support of such a role in TNBC patients, a survey of 138 clinical TNBC samples shows significant correlations between increased ERR $\alpha$ levels and higher breast cancer grade, metastasis, and unfavorable outcome. In addition, the expression of ERR $\alpha$ and $\mathrm{FN}$ is significant positively correlated with each other in $65.2 \%$ TNBC patients. This suggests that over expression of ERR $\alpha$ might trigger the metastasis of TNBC cells via promoter EMT process in human body through up regulation of FN. Our study also revealed that ERR $\alpha$ has the potential to be used as a marker of unfavorable prognosis of TNBC.

Our findings are important for several reasons. We show that ERR $\alpha$ acts as mesenchymal function, which provides another mechanism for the aggressive phenotype of TNBC. We also present for the first time that ERR $\alpha$ can directly bind to the promoter of $F N$ and then increase its expression. Further, ERR $\alpha$ can be an independent prognostic marker and a unique therapeutic target, with particular relevance to clinically aggressive TNBC. In summary, our results, taken together with published literatures, establish an essential role of ERR $\alpha$ in TNBC progression and position it as an important target for TNBC treatment. Considering that there is no efficiency therapy target for TNBC, our findings are encouraging and suggest that ERR $\alpha$ could be targeted for TNBC treatment in the future.

\section{MATERIALS AND METHODS}

\section{Reagents}

PD 98059 (PD, MAPK/ERK kinase inhibitor), SP600125 (SP, JNK inhibitor), SB203580 (SB, p38MAPK inhibitor), LY294002 (LY, PI3K/Akt inhibitor), H89 (PKA inhibitor), BAY11-7082 (BAY, NF-кB inhibitor) were obtained from Sigma-Aldrich (St Louis, Mo., USA). XCT-790 (specific inverse agonist of ERR $\alpha$ ) and other chemicals were of reagent grade or better and purchased from Sigma Chemical Co. (St. Louis, MO, USA) unless otherwise noted. Monoclonal antibodies against FN, E-Cad, Vim, Snail, Slug, Twist, ZEB, p-ERK1/2, ERK1/2, p-JNK, JNK, p-p38 MAPK, p38 MAPK, p-p65, p65, p-IкB, IкB, p-p53, p53, p-Smad2, Smad2, p-Stat3, Stat3, and GAPDH were purchased from Cell Signaling Technology Inc. (Beverly, MA, USA). Antibodies against p-Akt and Akt were purchased from Bioworld Technology, Inc (Minneapolis, MN, USA). Horseradish peroxidase-conjugated secondary antibody from Santa Cruz Biotechnology (Santa Cruz, CA, USA). All compounds were solubilized in DMSO. Medium containing $0.5 \%$ DMSO was used as the control.

\section{Cell culture and transfection}

Cancer cell MCF-7, T47D, SkBr3, HS578T, MDAMB-231, BT-549, PC3, HepG2, and SkBr3 cells were purchased from the American Type Culture Collection (Manassas, VA, USA), maintained in our laboratory, and cultured in RPMI 1640 or DMEM medium (Invitrogen Corporation, Carlsbad, CA, USA) supplemented with $10 \%$ heat-inactivated fetal Bovin serum, $100 \mathrm{U} / \mathrm{ml}$ penicillin, and $10 \mu \mathrm{g} / \mathrm{ml}$ streptomycin at $37^{\circ} \mathrm{C}$ in a $5 \%$ $\mathrm{CO}_{2}$ atmosphere. An ABI 3130 Genetic Analyzer (Applied 
Biosystems) was used for the profiling. The DNA profile data were cross-checked with the ATCC data bank. Medium was replaced with phenol red-free medium $24 \mathrm{~h}$ before experiments to remove the estrogen-like activity of phenol red. For transfection, cells were seeded into sixwell plates and transfectd with pcDNA3.1 (vector control), ERR $\alpha$ construct (purchased from Addgene, Cambridge, MA), siRNA negative control (siRNA-NC: 5'-GGC TAC GTC CAG GAG CGC A-3'), or si-ERR $\alpha$ (sequence 5'GAG CAU CCC AGG CUU CUC A dT dT-3') by use of Lipofectamine 2000 reagent (Invitrogen).

\section{In vitro wound-healing and transwell invasion assay}

A wound-healing assay was used to compare the migratory ability of MDA-MB-231 and BT549 cells as described previously [36]. The cell migration and invasion assay was using 6-well transwell plates (Falcon cell culture inserts, $8-\mu \mathrm{m}$ pore size, BD, NJ) according to our previous study [37]. The in vitro wound-healing and transwell invasion assays were carried out at least 5 individual experiments.

\section{Western blotting analysis}

Western blotting was performed as previously described [38].

\section{Quantitative real-time PCR}

After treatment as indicated, total mRNA of cells was extracted with TRIZOL reagent. Then the quantitative real-time PCR for gene expression were conducted as our previous method [36]. Transcripts of the housekeeping gene GAPDH in the same incubations were used for internal normalization. Primer pairs were as follows: FN, forward 5'- CCC AGA CTT ATG GTG GCA ATT C-3' and reverse 5'- AAT TTC CGC CTC GAG TCT GA-3'; E-Cad forward 5'- TAC ACT GCC CAG GAG CCA GA -3' and reverse 5'- TGG CAC CAG TGT CCG GAT TA -3'; Vim forward 5'- TGA GTA CCG GAG ACA GGT GCA G -3' and reverse 5'- TAG CAG CTT CAA CGG CAA AGT TC3'; ERR $\alpha$ forward 5'-CA ATG AGT GTG AGA TCA CC $-3^{\prime}$ and reverse 5'-CCG TTT GTA CTT CTG CCG TC-3'.

\section{Reporter genes assay}

The pGL3-Basic-FN-luc which contains FN promoter with the sequence $-998 /+28$ was the gift from Dr Tian Lan at Guangdong Pharmaceutical University. For measuring the transcriptional activity of $\mathrm{FN}$, cells were transfected with $0.2 \mu \mathrm{g}$ DNA $/ \mathrm{cm}^{2}$ per plasmid and lipofectamine 2000 reagent (Invitrogen, USA) according to the manufacturer's instructions, and then treated with XCT-790 for the indicated times. Transfection efficiency was normalized by cotransfection with pRL-TK. Transcriptional activity was determined by a luminometer, using a dual-luciferase assay kit. Results were displayed as the ratios between the activity of the reporter plasmid and pRL-TK [37].

\section{Chromatin immunoprecipitation (ChIP)}

ChIP assays were performed on MDA-MB-231 cells as previously described [20]. Briefly, cells were incubated for $10 \mathrm{~min}$ in phosphate-buffered saline containing $1 \%$ formaldehyde. After sonication with Bioruptor (Diagenode, Liège, Belgium), soluble chromatin fragments of 200 to $1000 \mathrm{bp}$ in length were incubated with $5 \mu \mathrm{g}$ of anti-hERR $\alpha$ antibody, rabbit anti-IgG antibody, or no antibody for $16 \mathrm{~h}$ at $4^{\circ} \mathrm{C}$, followed by incubation with $80 \mu \mathrm{g}$ of salmon sperm DNA/protein A-agarose for $2 \mathrm{~h}$ at $4^{\circ} \mathrm{C}$. Immunoprecipitates were washed and eluted. Samples were then treated with RNase A (Roche Diagnostics) for 30 minutes at $37^{\circ} \mathrm{C}$ and with proteinase $\mathrm{K}$ (Roche Diagnostics) for $2 \mathrm{~h}$ at $42^{\circ} \mathrm{C}$. Isolated DNA fragments were purified with QIAquick spin kit (Qiagen), and quantitative PCRs were performed using $2 \mu \mathrm{l}$ of DNA in triplicate. The promoter of FN ( -998 to +199) was scanned for putative ERREs using the MAPPER search engine [39]. The primers for four ERRE sites were listed at Supplementary Table S1.

\section{Animal experiments}

Nude mice were purchased from the Sun Yat-sen University (Guangzhou, China) Animal Center and raised under pathogen-free conditions. All animal experiments complied with the Zhongshan School of Medicine Policy on the Care and Use of Laboratory Animals. MDA-MB-231 cells $\left(2 \times 10^{6}\right.$ per mouse $)$ suspended in $100 \mu 1640$ medium were injected into the fourth right mammary fat pad at the base of the nipple of nude mice $(n=9)$ with $50 \%$ Matrigel (BD bioscience, Bedford, MA). When the tumor was visible, mice of XCT-790 group were treated with XCT-790 (4 mg per $\mathrm{kg}$, body weight) by tail vein injection for six times for every three days. When tumor volume at the control group reached approximate $1000 \mathrm{~mm}^{3}$, mice were sacrificed, and the tumors were removed and weighed for use in histology and Western blot analysis. Tumor burden in the lung was quantified by manually counting nodules visible on the lung surface. Tumors and lungs were embedded in paraffin for further study.

\section{Patients and tissue samples}

The study included a group of 138 clinicalpathological characterized patients with histologically confirmed triple-negative breast cancer (TNBC) from the Affiliated Cancer Hospital of Guangzhou Medical University and the Cancer Center of Sun Yatsen University between 2005 to 2014. For all of the patients who participated in this study, written informed 
consent was obtained, which was approved by the Ethical Committee of Sun Yat-sen University according to the Chinese Ethical Regulations. All samples were tissues collected surgically under the supervision of an experienced pathologist. After collection, samples were stored at $-80^{\circ} \mathrm{C}$ until used. Clinical data were reviewed retrospectively from medical records. The detailed clinical and pathological characteristics of tumor tissues were described in Table 1.

\section{Tumor histology and immunohistochemistry}

Immunohistochemistry staining of formalin-fixed paraffin-embedded tissue was conducted as previously described [40]. Briefly, tumor tissues (both mice and human) and lungs (mice) were fixed in formalin and embedded in paraffin. Sections $(5 \mathrm{~mm})$ were cut and stained with H\&E. For immunohistochemical staining, sections were deparaffinized and hydrated, and endogenous peroxidase activity was blocked with $3 \%$ $\mathrm{H}_{2} \mathrm{O}_{2}$ in water for $10 \mathrm{~min}$. Antigen retrieval was done with $10 \mathrm{mM}$ citrate buffer (pH6.0) for $10 \mathrm{~min}$. Slides were incubated with Biocare blocking reagent for $10 \mathrm{~min}$ to block nonspecific binding. Then, they were incubated with anti- ERR $\alpha$, E-Cad, or FN overnight at $4{ }^{\circ} \mathrm{C}$. Slides were washed in PBS twice and then incubated with goat anti-rabbit horseradish peroxidase-conjugated secondary antibodies for $30 \mathrm{~min}$ at room temperature and then washed. Finally, slides were incubated with 3, 3'-diaminobenzidine and counter stained with hematoxylin.

\section{Statistical analysis}

All values were reported as mean \pm SD unless otherwise specified. Data were analyzed by two-tailed unpaired Student's $t$-test between two groups and by OneWay ANOVA followed by Bonferroni test for multiple comparison involved. The $\chi^{2}$ test or Fisher's exact test was used to analyze the association of ERR $\alpha$ expression and clinical-pathological parameters or ERR $\alpha$ and FN expression in clinical tissues. The survival curves were plotted by using Kaplan-Meier analysis. Statistical analysis was carried out using SPSS 16.0 for Windows. A $p$-value of $<0.05$ was considered to be statistically significant.

\section{ACKNOWLEDGMENTS}

This research was supported by the National Natural Science Foundation of China (Grant No. 81472470 and No. 81302317), the Guangdong Natural Science Funds for Distinguished Young Scholar (No. 2014A030306025), the Pearl River S\&T Nova Program of Guangzhou (No. 201506010039), the Fundamental Research Funds for the Central Universities (Sun Yat-sen University) (No.12ykpy09), the Science and Technology Planning Project of Guangdong Province, China (No. 2012B031500005), and the Opening
Project Program of State Key Laboratory of Oncology in South China (No. HN2014-09).

\section{CONFLICTS OF INTEREST}

The authors declare no conflict of interest.

\section{REFERENCES}

1. Kirkpatrick P. Targeting triple-negative breast cancer. Nat Rev Drug Discovery. 2009; 8:21-21.

2. Gilbert JA. Potential therapeutic target for triple-negative breast cancer. Lancet Oncol. 2012; 13:e330.

3. Thiery JP, Acloque H, Huang RYJ, Nieto MA. Epithelialmesenchymal transitions in development and disease. Cell. 2009; 139:871-890.

4. Polyak K, Weinberg RA. Transitions between epithelial and mesenchymal states: acquisition of malignant and stem cell traits. Nat Rev Cancer. 2009; 9:265-273.

5. Craene BD, Berx G. Regulatory networks defining EMT during cancer initiation and progression. Nat Rev Cancer. 2013; 13:97-110.

6. Singh A, Settleman J. EMT, cancer stem cells and drug resistance: an emerging axis of evil in the war on cancer. Oncogene. 2010; 29:4741-4751.

7. Tiwari N, Gheldof A, Tatari M, Christofori G. EMT as the ultimate survival mechanism of cancer cells. Semin Cancer Biol. 2012; 22:194-207.

8. Mostert B, Sleijfer S, Foekens JA, Gratama JW. Circulating tumor cells (CTCs): Detection methods and their clinical relevance in breast cancer. Cancer Treat Rev. 2009; $35: 463-474$.

9. Zeng Q, Li W, Lu D, Wu Z, Duan H, Luo Y, Feng J, Yang D, Fu L, Yan X. CD146, an epithelial-mesenchymal transition inducer, is associated with triple-negative breast cancer. Proc Natl Acad Sci. 2012; 109:1127-1132.

10. Saini KS, Loi S, de Azambuja E, Metzger-Filho O, Saini ML, Ignatiadis M, Dancey JE, Piccart-Gebhart MJ. Targeting the $\mathrm{PI} 3 \mathrm{~K} / \mathrm{AKT} / \mathrm{mTOR}$ and Raf/MEK/ERK pathways in the treatment of breast cancer. Cancer Treat Rev. 2013; 39:935-946.

11. Giguere V, Yang N, Segui P, Evans RM. Identification of a new class of steroid hormone receptors. Nature. 1988; 331:91-94.

12. Giguere V. Transcriptional Control of Energy Homeostasis by the Estrogen-Related Receptors. Endocr Rev. 2008; 29:677-696.

13. Tennessen JM, Baker KD, Lam G, Evans J, Thummel CS. The Drosophila Estrogen-Related Receptor Directs a Metabolic Switch that Supports Developmental Growth. Cell Metab. 2011; 13:139-148.

14. Cai Q, Lin T, Kamarajugadda S, Lu J. Regulation of glycolysis and the Warburg effect by estrogen-related receptors. Oncogene. 2012; 32:2079-2086. 
15. Ariazi EA, Clark GM, Mertz JE. Estrogen-related receptor alpha and estrogen-related receptor gamma associate with unfavorable and favorable biomarkers, respectively, in human breast cancer. Cancer Res. 2002; 62:6510-6518.

16. Suzuki T, Miki Y, Moriya T, Shimada N, Ishida T, Hirakawa H, Ohuchi N, Sasano H. Estrogen-related receptor $\alpha$ in human breast carcinoma as a potent prognostic factor. Cancer Res. 2004; 64:4670-4676.

17. Stein RA, Chang CY, Kazmin DA, Way J, Schroeder T, Wergin M, Dewhirst MW, McDonnell DP. Estrogen-related receptor alpha is critical for the growth of estrogen receptornegative breast cancer. Cancer Res. 2008; 68:8805-8812.

18. Deblois G, Giguere V. Oestrogen-related receptors in breast cancer: control of cellular metabolism and beyond. Nat Rev Cancer. 2013; 13:27-36.

19. Chisarnore MJ, Wilkinson HA, Flores O, Chen JD. Estrogen-related receptor-alpha antagonist inhibits both estrogen receptor-positive and estrogen receptor-negative breast tumor growth in mouse xenografts. Mol Cancer Ther. 2009; 8:672-681.

20. Bianco S, Lanvin O, Tribollet V, Macari C, North S, Vanacker JM. Modulating estrogen receptor-related receptor-alpha activity inhibits cell proliferation. J Biol Chem. 2009; 284:23286-23292.

21. Deblois G, Chahrour G, Perry MC, Sylvain-Drolet G, Muller WJ, Giguere V. Transcriptional Control of the ERBB2 Amplicon by ERR alpha and PGC-1 beta Promotes Mammary Gland Tumorigenesis. Cancer Res. 2010; 70:10277-10287.

22. Dwyer MA, Joseph JD, Wade HE, Eaton ML, Kunder RS, Kazmin D, Chang CY, McDonnell DP. WNT11 Expression Is Induced by Estrogen-Related Receptor alpha and betaCatenin and Acts in an Autocrine Manner to Increase Cancer Cell Migration. Cancer Res. 2010; 70:9298-9308.

23. Fradet A, Sorel H, Bouazza L, Goehrig D, Depalle B, Bellahcene A, Castronovo V, Follet H, Descotes F, Aubin JE, Clezardin P, Bonnelye E. Dual function of ERRalpha in breast cancer and bone metastasis formation: implication of VEGF and osteoprotegerin. Cancer Res. 2011; 71:5728-5738.

24. Ao A, Wang H, Kamarajugadda S, Lu J. Involvement of estrogen-related receptors in transcriptional response to hypoxia and growth of solid tumors. Proc Natl Acad Sci. 2008; 105:7821-7826.

25. Stein RA, Gaillard S, McDonnell DP. Estrogen-related receptor alpha induces the expression of vascular endothelial growth factor in breast cancer cells. J Steroid Biochem Mol Biol. 2009; 114:106-112.

26. Tiraby C, Hazen BC, Gantner ML, Kralli A. EstrogenRelated Receptor Gamma Promotes Mesenchymal-toEpithelial Transition and Suppresses Breast Tumor Growth. Cancer Res. 2011; 71:2518-2528.

27. Sailland J, Tribollet V, Forcet C, Billon C, Barenton B, Carnesecchi J, Bachmann A, Gauthier KC, Yu S, Giguere V,
Chan FL, Vanacker JM. Estrogen-related receptor a decreases RHOA stability to induce orientated cell migration. Proc Natl Acad Sci. 2014; 111:15108-15113.

28. Bardet PL, Horard B, Laudet V, Vanacker JM. The ERRalpha orphan nuclear receptor controls morphogenetic movements during zebrafish gastrulation. Dev Biol. 2005; 281:102-111.

29. Jarzabek K, Koda M, Kozlowski L, Sulkowski S, Kottler ML, Wolczynski S. The significance of the expression of ERR alpha as a potential biomarker in breast cancer. J Steroid Biochem Mol Biol. 2009; 113:127-133.

30. Chang CY, Kazmin D, Jasper JS, Kunder R, Zuercher WJ, McDonnell DP. The metabolic regulator ERRalpha, a downstream target of HER2/IGF-1R, as a therapeutic target in breast cancer. Cancer Cell. 2011; 20:500-510.

31. Mani SA, Guo W, Liao MJ, Eaton EN, Ayyanan A, Zhou AY, Brooks M, Reinhard F, Zhang CC, Shipitsin M, Campbell LL, Polyak K, Brisken C, Yang J, Weinberg RA. The epithelial-mesenchymal transition generates cells with properties of stem cells. Cell. 2008; 133:704-715.

32. Ferrari-Amorotti G, Chiodoni C, Shen F, Cattelani S, Soliera AR, Manzotti G, Grisendi G, Dominici M, Rivasi F, Colombo MP, Fatatis A, Calabretta B. Suppression of invasion and metastasis of triple-negative breast cancer lines by pharmacological or genetic inhibition of slug activity. Neoplasia. 2014; 16:1047-1058.

33. Lam SS, Mak AS, Yam JW, Cheung AN, Ngan HY, Wong AS. Targeting estrogen-related receptor alpha inhibits epithelial-to-mesenchymal transition and stem cell properties of ovarian cancer cells. Mol Ther. 2014; 22:743-751.

34. Shan SW, Lee DY, Deng ZQ, Shatseva T, Jeyapalan Z, Du WW, Zhang Y, Xuan JW, Yee SP, Siragam V, Yang BB. MicroRNA MiR-17 retards tissue growth and represses fibronectin expression. Nat Cell Biol. 2009; 11:1031-U1278.

35. Bianco S, Sailland J, Vanacker JM. ERRs and cancers: Effects on metabolism and on proliferation and migration capacities. J Steroid Biochem Mol Biol. 2012; 130:180-185.

36. Chen ZJ, Yang XL, Liu H, Wei W, Zhang KS, Huang HB, Giesy JP, Liu HL, Du J, Wang HS. Bisphenol A modulates colorectal cancer protein profile and promotes the metastasis via induction of epithelial to mesenchymal transitions. Arch Toxicol. 2015; 89:1371-81.

37. Jiang GM, Wang HS, Zhang F, Zhang KS, Liu ZC, Fang R, Wang H, Cai SH, Du J. Histone deacetylase inhibitor induction of epithelial-mesenchymal transitions via up-regulation of Snail facilitates cancer progression. BBA-Mol Cell Res. 2013; 1833:663-671.

38. Ge LC, Chen ZJ, Liu HY, Zhang KS, Liu H, Huang HB, Zhang G, Wong CK, Giesy JP, Du J, Wang HS. Involvement of activating ERK1/2 through $\mathrm{G}$ protein coupled receptor 30 and estrogen receptor alpha/beta in low 
doses of bisphenol A promoting growth of Sertoli TM4 cells. Toxicol Lett. 2014; 226:81-89.

39. Marinescu VD, Kohane IS, Riva A. MAPPER: a search engine for the computational identification of putative transcription factor binding sites in multiple genomes. BMC Bioinformatics. 2005; 6:79.
40. Liu H, Zhou BH, Qiu X, Wang HS, Zhang F, Fang R, Wang XF, Cai SH, Du J, Bu XZ. T63, a new 4-arylidene curcumin analogue, induces cell cycle arrest and apoptosis through activation of the reactive oxygen species-FOXO3a pathway in lung cancer cells. Free Radic Biol Med. 2012; 53:2204-2217. 